\title{
Correction to: CAERS: A Conversational Agent for Intervention in MOOCs' Learning Processes
}

\author{
Diego Rossi, Victor Ströele, Regina Braga, Santi Caballé, \\ Nicola Capuano, Fernanda Campos, Mário Dantas, Luigi Lomasto, \\ and Daniele Toti
}

\section{Correction to: \\ Chapter "CAERS: A Conversational Agent for Intervention in MOOCs' Learning Processes" in: D. Guralnick et al. (Eds.): \\ Innovations in Learning and Technology for the Workplace and Higher Education, LNNS 349, https://doi.org/10.1007/978-3-030-90677-1_36}

In the original version of the chapter, the following belated correction has been incorporated: The author name "Danielle Toti" has been changed to "Daniele Toti". The chapter has been updated with the change. 